\title{
A psicologia da religião como instrumento de integração do humano
}

\author{
The psychology of religion as an instrument for the \\ integration of the human
}

\section{La psicología de la religión como instrumento para la integración del humano}

\author{
$\underline{\text { Rogério de Assis }}$ \\ Juliano Bernardino de Godoy
}

RESUMO

O presente artigo versa sobre psicologia da religião com base em C.G.Jung em sua obra "Psicologia e Religião" (1999) e demais autores. Consequentemente, esclarece que tal área do saber não se dedica sobre o estudo de uma religião em si, mas sim sobre "O Fenômeno Religioso" (2004) que perpassa toda e qualquer religião conforme nos ensina Tommy Akira Goto. Estuda também que o humano em sua imanência e transcendência necessita de um olhar mais atento sobre si mesmo com o objetivo de compreender-se em seu aspecto complexo em meio ao mundo que o cerca. Indivíduo este que pensa, ora, chora, se alegra, ama, sente raiva, se angustia, se frustra e por isso mesmo sente necessidade de completar-se uma vez que se entende pequeno, cansado e muitas vezes vazio. Nesse sentido, estudar-se-á também ao longo do artigo tanto os aspectos individuais quanto coletivos das manifestações religiosas e o seu poder curativo. Por fim, concluir-se-á que a psicologia da religião é muito mais do que num primeiro momento se possa imaginar, ela é peça fundamental na compreensão dos fenômenos religiosos. Portanto, deve ser mais valorizada nas práticas pastorais e comunitárias que são antigas e novas.

Palavras-chave: Psicologia da religião; experiencia religiosa; integração; transcendência; práticas comunitárias e pastorais.

\begin{abstract}
This article deals with the psychology of religion based on C.G.Jung in his work "Psychology and Religion" (1999) and other authors. Consequently, he clarifies that this area of knowledge is not dedicated to the study of a religion itself, but to "The Religious Phenomenon" (2004) that permeates any and every religion as taught by Tommy Akira Goto. It also studies that the human in its immanence and transcendence needs a closer look at itself in order to understand itself in its complex aspect in the world that surrounds it. An individual who thinks, prays, cries, rejoices, loves, feels anger, anguishes, gets frustrated and therefore feels the need to complete himself once he feels small, tired and often empty. In this sense, both the individual and collective aspects of religious manifestations and their curative power will also be studied throughout the article. Finally, it will be concluded that the psychology of religion is much more than at first imagined, it is a fundamental part in the understanding of religious phenomena. Therefore, it must be more valued in pastoral and community practices that are old and new.
\end{abstract}

Keywords: Psychology of religion; religious experience; integration; transcendence; community and pastoral practices. 


\section{RESUMEN}

Este artículo trata sobre la psicología de la religión basada en CG Jung en su trabajo "Psicología y religión" (1999) y otros autores. En consecuencia, aclara que esta área de conocimiento no está dedicada al estudio de una religión en sí misma, sino al "Fenómeno religioso" (2004) que impregna todas y cada una de las religiones como lo enseña Tommy Akira Goto. También estudia que el humano en su inmanencia y trascendencia necesita una mirada más cercana a sí mismo para entenderse a sí mismo en su aspecto complejo en el mundo que lo rodea. Una persona que piensa, reza, llora, se regocija, ama, siente enojo, angustia, se frustra y, por lo tanto, siente la necesidad de completarse una vez que se siente pequeño, cansado y con frecuencia vacío. En este sentido, los aspectos individuales y colectivos de las manifestaciones religiosas y su poder curativo también se estudiarán a lo largo del artículo. Finalmente, se concluirá que la psicología de la religión es mucho más de lo que se imaginó al principio, es una parte fundamental en la comprensión de los fenómenos religiosos. Por lo tanto, debe valorarse más en las prácticas pastorales y comunitarias que son antiguas y nuevas.

Palabras clave: Psicología de la religión; experiencia religiosa; integración; trascendencia; prácticas comunitarias y pastorales.

\section{Introdução}

Não há quem questione o fato de que, desde os tempos ancestrais, a religião vem ocupando um espaço de extrema importância - quiçá central, como a fonte decisiva no comportamento e nas relações na vida da humanidade. No entanto, diante do desenvolvimento das ciências do espírito a partir do final do século XIX, é sempre pertinente se questionar em que medida uma ciência como a psicologia pode se relacionar com a religião. Será que elas são incompatíveis? Ou, pensando de outra forma, será que a abordagem psicológica poderia servir para o aprofundamento e amadurecimento da experiência religiosa? Essas provocações iniciais nos levam ao encontro de Rosileny Alves dos Santos em seu livro intitulado "Entre a Razão e o Êxtase: experiência religiosa e estados alterados de consciência", onde se lê na apresentação de (BOFF, 2004).

O Sagrado, o Divino, O Mistério, numa palavra, a realidade de Deus, possui esta natureza, a de nos absorver totalmente, de nos transportar a um outro nível e de nos transformar. Pode ser uma experiencia de fascínio, que atrai irrefreavelmente buscando uma união, ou pode ser uma experiencia de temor, que nos obriga instintivamente a baixar os olhos ou até a fugir pelo excesso de luz. Tanto um caso como o outro têm a ver com algo que nos toma totalmente, que nos afeta incondicionalmente e que se relaciona com o sentido supremo de nossa vida. Por isso, o êxtase implica sempre uma ampliação da consciência e um fortalecimento das razões de existir.

Iniciamos nossa exposição buscando uma breve definição do que viria a ser psicologia. Para além do simples "discurso acerca da mente" (psikos+logos), segundo pontua R. Bultmann, "a psicologia pode ser entendida como um grupo de esforços genéricos para estudar cientificamente o comportamento humano" (ELWELL, 1990, p. 202). 
Por outro lado, é preciso que também tenhamos uma visão adequada sobre o que é a religião. Esta, de acordo com Jung "poderíamos, portanto, dizer que o termo "religião" designa a atitude particular de uma consciência transformada pela experiencia do numinoso." (JUNG, 1999, p. 10). A psicologia da religião nesse sentido, não está preocupada com uma religião específica, no sentido de um sistema organizado de crenças, mas com um sentimento que nos parece universal e que nos impulsiona em direção ao "Totalmente Outro". Nesse sentido:

A "experiência religiosa" refere-se à experiência da realidade, da presença e da atividade de um Ser Supremo, do Sagrado, ou de Deus. Ou, em outras palavras, a experiência religiosa é a resposta do indivíduo, primariamente em termos cognitivos e emocionais, a qualquer coisa que ele considera divina e essa experiência é a base das práticas religiosas. (...) Assim, a "experiência religiosa" é uma consciência direta e imediata daquilo que transcende o intelecto e vontade, sujeito e objeto. Segundo Friedrich Schleiermacher a "experiência religiosa" é a experiência da dependência absoluta. (FARRIS, 2002, p. 27, 28).

E ainda recorrendo a Jung no que tange ao pensamento do que vem a ser a Psicologia da Religião e qual é o papel do psicólogo(a) ao lidar com fenômenos de natureza religiosa que perpassam o campo da experiencia, lê-se:

O psicólogo, que se coloca numa posição puramente científica, não deve considerar a pretensão de todo credo religioso: a de ser o possuidor da verdade exclusiva eterna. Uma vez que trata da experiência religiosa primordial, deve concentrar sua atenção no aspecto humano do problema religioso, abstraindo o que as confissões religiosas fizeram com ele. (JUNG, 1999, p. 11).

Mas qual seria a relação entre a psicologia e a religião? Muitos psicólogos e psiquiatras já tentaram responder a essa questão. Dois exemplos que resumem a questão da abordagem da religião feita pela ciência lemos em (HOUTARD, 2003, p. 33-34):

Dentro da grande corrente de pensamento iniciada por Sigmund Freud e continuada por C.G. Jung assim como por Lacan encontramos outro tipo de interpretação dos fatos religiosos. De acordo com ela, o simbolismo religioso chega a inibir, encobrir e assumir representações arcaicas por meio de processos de metaforização ou de sublimação. Para Freud, isso significa uma ilusão e uma forma de neurose. Desse modo, explica a ideia de Deus como resultado do complexo de Édipo, fruto do instinto sexual monopolizado por um pai todo-poderoso, morto pelos filhos que desenvolvem ritos de expiação. Daí a natureza afetiva da religião e seu grande poder de mobilização que, no entanto, é ilusório e consequentemente negativo. Jung, ao contrário, atribui valor positivo a todas as religiões.

Como se pode observar, existem os que acreditam que a religião é algo ruim e que deve ser exorcizada da vida das pessoas e, existem os que acreditam 
que ela pode contribuir para o próprio desenvolvimento pessoal do indivíduo. Neste breve trabalho, tem-se a pretensão de definir a questão, delinear seu raio de ação e expor as principais teses ou caminhos que abordam a questão. Por fim, serão apresentadas as considerações finais e as devidas referências.

\section{Definindo a questão}

Com base na definição dada acima, a psicologia da religião, pode ser objeto de entendimento tanto em termos de sua definição funcional, quanto em termos de sua definição substantiva. Assim, para

A definição funcional da religião enfatiza o processo mediante o qual os seres humanos procuram responder aos enigmas da vida e definir o seu significado pela fé. A definição substantiva da religião ressalta o produto da fé no qual aqueles que se reúnem em torno de ideias transpessoais são rotulados como religiosos. (ELWELL, 1990, p. 202).

Ao se levar em conta qualquer uma das duas formas diferentes de observar o fenômeno religioso apontado acima, apesar das tensões que essa breve exposição possa trazer, Bultmann compreende que a psicologia "da" religião pode ser vista como "o esforço para reduzir a religião à dinâmica da psicologia ou como a tentativa de compreender mais plenamente a relevância desse processo para a religião" (ELWELL, 1990, p. 202).

Em sua exposição, Bultmann também faz referência à psicologia "através" da religião, que seria o inverso do processo acima, ou seja, seria um instrumento por meio do qual a religião, ou a análise normativa da nossa natureza humana, nos permitira observar ou ter uma compreensão psicológica das pessoas; e também fala de uma psicologia "com" a religião, vislumbrada como um esforço para que possamos obter uma interpretação psicológica e religiosa dos mesmos fenômenos.

É possível então pensar na relação entre psicologia e religião a partir da sua relação "pró/contra". Neste sentido, se está diante de uma tentativa de "usar a psicologia para autenticar a religião ou para invalidá-la" (ELWELL, 1990, p. 203).

Caminhando agora na direção de uma integração, fica claro que psicologia e religião ou religião e psicologia estão totalmente imbricadas como um "fenômeno" antigo, atual e complexo humano. Tommy Akira Goto, deixa a

\footnotetext{
Aqui a palavra "fenômeno" é extraída da obra de Tommy Akira Goto, intitulada "O Fenômeno Religioso: a fenomenologia em Paul Tillich" (devidamente citada nas referências deste artigo). Nesse sentido, deve ser compreendida conforme proposta pelo autor, ou seja, "como um método, uma atitude e não uma doutrina filosófica”. Método este que busca entender e discutir sobre as relações do humano com o mundo que o cerca em todos os seus aspectos com vias a sua integração, sua correlação.
} 
sua contribuição nesse sentido ao dizer: "mostra também como a fenomenologia da religião se constituiu enquanto disciplina autônoma, enquanto" (GOTO, 2004, p. 8) "estudo sistemático do fato religioso nas manifestações e expressões sensíveis, ou seja, do comportamento humano, com a finalidade de apreender o seu significado profundo" (GOTO, 2004, p. 8).

O ser humano como supracitado se alegra, chora, ri, se angustia, e ao mesmo tempo busca entender toda essa gama de sentimentos com a finalidade de compreender-se. E onde busca essa compreensão? Na religião e na psicologia, ou ainda, na psicologia da religião. Dai a importância das religiões de modo geral serem e terem espaços terapêuticos, de escuta, de integração do humano, tanto em seu aspecto individual quanto comunitário. Seria então essa metodologia, esse modo de ser e de agir considerado uma ciência? Uma ciência que busca conhecer e investigar o mais profundo do ser humano com vistas a ajudá-lo a se conhecer, a se integrar fazendo uso do instrumental psicológico e teológico presente em cada denominação religiosa? Nesse ponto da reflexão, sem dúvida alguma não se pode deixar de mencionar a "fenomenologia". Fenomenologia esta que "é método e atitude filosófica que influenciou o estudo no campo da religião, se desenvolvendo em duas direções: como fenomenologia da religião e como método de investigação na teologia" (JUNG, 2004, p. 15).

Ora, se para que uma atividade possa ser considerada uma ciência, ela precisa ter um objeto de pesquisa e um método de abordagem, Benkö nos diz que W. Keilbach coloca a psicologia religiosa entre as ciências da religião "porque o seu objeto é o do campo religioso" (BENKÖ, 1981, p. 15) e porque considera o método de investigação enquadrando-a dentre as disciplinas psicológicas. Por tudo isso, ela sempre foi considerada uma ciência de fronteira. Benkö entende que "a psicologia religiosa é aquele ramo da psicologia que investiga as experiências, comportamentos e expressões religiosas sob ângulo psicológico" (BENKÖ, 1981, p. 15).

Para o conhecido psicólogo e pastor batista Merval Rosa, a psicologia da religião diz respeito ao "estudo do fenômeno religioso do ponto de vista psicológico, ou seja, a aplicação dos princípios e métodos da psicologia ao estudo científico do comportamento religioso do homem, quer como indivíduo, quer como membro de uma comunidade religiosa" (ROSA, 1979, p. 15).

Vê-se então que, quando se refere ao "comportamento religioso", ele se refere a qualquer espécie de ato ou gesto, individual ou coletivo, público ou privado, que faça uma referência específica ao divino ou ao sobrenatural. Neste sentido, ele ressalta que a psicologia da religião "não é nem a defesa nem a condenação da religião" (ROSA, 1979, p. 15), mas o estudo meramente 
descritivo e - no que for possível -, objetivo, do fenômeno religioso onde quer que ele surja. Dessa forma, o psicólogo da religião tanto pode examinar cientificamente um indivíduo ou um grupo, de uma perspectiva objetiva, ou seja, voltando-se para expressões como a oração, a conversão ou as experiências místicas individuais ou grupais. Fato é: é perfeitamente possível investigar e promover a integração do humano através de um estudo sistematizado. De acordo com o livro $A$ Religião do Cérebro (MARINO JUNIOR, 2005, p.14):

Um dos neurocientistas mais importantes do último século, sir John Eccles, ganhador do Prêmio Nobel de Fisiologia em 1963 por ter sido o primeiro a registrar a atividade elétrica do corpo celular de um neurônio isolado dentro de seu próprio citoplasma, afirmou, em 1994, que deve haver uma interação entre a alma e o cérebro.

Nesse sentido, há uma quebra o tabu no que tange a discussão das questões religiosas e psicológicas do ponto de vista científico, desvelando quão complexo e bonito é o ser humano em suas multifacetadas capacidades de ser. E finalizando esse ponto, William James, um dos pais da moderna psicologia escreveu em seu livro The Varities of Religious Experience (1925): "Para alcançar uma ciência crítica sobre as religiões, o material básico deve proceder de fatos da experiencia pessoal” (MARINO JUNIOR, 2005, p. 15).

\section{Delineando o raio de ação}

Em uma comparação extremamente pertinente e feliz entre a sociologia da religião e a psicologia da religião, José Severino Croatto diz que, “assim como os fatos religiosos são o espelho de uma determinada sociedade (sociologia da religião), da mesma maneira podem ser espelhos da psique humana" (CROATTO, 2001, p. 19). O que se verifica aqui lembra um círculo vicioso já que não existe religião sem pessoas e a religião é uma experiência essencialmente pessoal, ou seja, sem o ser humano não existe experiência religiosa e sem experiência religiosa, não existem seres humanos. A religião, conforme é sabido, - expressa nas suas formas mais diversas - é um elemento presente em todas as culturas humanas. Elemento este fundamental também para regular as relações humanas para o bem, uma vez que leva ao que crê praticar a sua fé observando um conjunto de regras de boa conduta que visam a sua transformação pessoal e comunitária, uma vez que o fenômeno religioso é vivido cá na terra, cá neste planeta, é aqui que seus valores devem ser postos em prática. (FORTE, 2006, p. 25).

Os seres humanos, devido à sua natureza corrupta e tiranizados pelo amor próprio, pelo qual só visam sobretudo, à própria utilidade [...], não devem forçar as paixões para 
endereçá-las à punição [...]. Portanto, não por outros, mas pela providência divina deve ser obrigado [...]. De modo que quem regula toda a correção dos seres humanos é a justiça divina, que nos é ministrada pela divina providência para conservar a sociedade humana. Portanto, essa Ciência, num de seus principais aspectos, deve ser uma teologia civil meditada sobre a providência divina.

Quando se verifica o raio de ação aplicado à psicologia da religião, pela literatura especializada, percebe-se que esse raio de ação é bastante amplo. Quando se observa o texto de Merval Rosa, percebe-se uma gama enorme de possibilidades. Lá vê-se que, em primeiro lugar, a psicologia da religião pode se dedicar ao estudo da experiência religiosa, tomando por critério o aspecto cronológico. Assim, é possível verificar a manifestação da religião (subjetiva ou objetiva) na infância, na adolescência, entre os adultos e na velhice. É claro que cada um desses períodos na vida do homem acaba por produzir consequências díspares em questões religiosas.

Em segundo lugar, a psicologia da religião pode se dedicar ao estudo da relação entre a dúvida e a fé, questionando os níveis e as funções da fé, bem como as causas da dúvida religiosa e suas consequências sobre a vida das pessoas.

Um terceiro assunto que a psicologia da religião pode se dedicar, diz respeito ao estudo do fenômeno da conversão religiosa. Este tema pode ser abordado tanto da perspectiva de cases a serem estudados (como o de Paulo, Francisco de Assis, John Bunyan ou Ramakrishna), ou da perspectiva do processo e dos elementos presentes em cada um dos casos apresentados, bem assim, sobre a temática da faixa etária em que ela ocorre.

Outro tema que poderia ser abordado pela psicologia da religião poderia ser o estudo do que é entendido por maturidade religiosa. Esta temática pode ser observada segundo pontua os grandes expoentes dessa ciência e procuraria responder a questões como: qual seria sua definição? Ou, como vislumbrar uma pessoa religiosamente madura?

Um quinto tema que poderia ser objeto de estudo da psicologia da religião poderia ser a experiência da oração e da adoração. Como ocorrem os cultos? Qual o papel de cada um na celebração? Qual o papel das mulheres no culto? Existem experiências extáticas relacionadas à oração ou ao culto? Quais são essas experiências? Qual o sexo e a faixa etária das pessoas mais propensas às experiências extáticas? ${ }^{2}$

\footnotetext{
2 Rosileny Alves dos Santos explica o que é êxtase religioso, diferenciando-o de transe. Ela escreveu: “[...] Para compreender o êxtase religioso, é preciso conhecer os símbolos que o envolvem. Os símbolos dão sentido ao êxtase. Podemos dizer que os símbolos por si só não explicam o êxtase, mas o promovem. Mas independentemente de valorizar os símbolos, Jung afirma que "as pessoas estão enfastiadas de tudo, dessa vida banal, e por isso querem sensações” (SANTOS, 2004, p. 39).
} 
A vocação religiosa poderia ser vista como uma sexta opção para os estudos da psicologia da religião. Neste aspecto, pode-se questionar sobre a idade, o sexo e o tipo de formação que os "vocacionados" possuem. Também pode-se verificar a relação que existe entre aqueles que possuem uma liderança carismática e os que possuem uma liderança organizacional e sua aceitação entre os membros da comunidade religiosa.

E ainda como sétima uma opção neste vasto campo de estudo, promovendo a interligação entre sociologia da religião, teologia da libertação e psicologia da religião seria o estudo dos aspectos do agir do humano do ponto de vista a transformá-lo baseado nos valores do já e do ainda não teológicos, ou seja, o entendimento de que o Reino de Deus já está em nós, mas ainda não em sua plenitude.

Por fim, mas sem pretender esgotar os temas, pode-se eleger a questão da saúde mental como objeto de pesquisa para a psicologia da religião. Em resumo, este tema procura discutir se as pessoas mais religiosas demonstram ter mais ou menos saúde em seus relacionamentos interpessoais.

É preciso que se compreenda que a abrangência dos estudos da psicologia da religião não se restringe aos temas que foram supracitados. Muito ao revés, entende-se que existam outras inúmeras áreas em que essa ciência pode abordar. Dito isso, é possível perceber o impacto científico que a psicologia da religião tem sobre questões da religião e sua relação com aspectos teológicos.

É claro que todos esses temas, bem assim como outros, podem ser examinados à luz de várias metodologias, alterando desde o behaviorismo até o existencialismo, passando a utilização de aspectos relacionados ao método de cálculos percentuais.

\section{Os principais caminhos a tomar}

Conforme observado, existem posições bastante antagônicas quanto a essa questão. Normalmente essas posições são exemplificadas na literatura pelas posturas de Freud e de Jung:

Segundo Freud, a religião é uma ilusão e uma das tarefas da psicanálise, do método por ele elaborado, é a liberação da humanidade da religião. A psicanálise freudiana apresenta-se, portanto, como crítica da religião. E nessa qualidade consagra H. Küng à psicanálise cerca de 80 páginas, no seu livro 'Existiert Gott' (Existe Deus?). C.G. Jung (1875-1961), numa certa época colaborador de Freud, chega a resultados opostos: a experiência religiosa constitui o critério da integração psicológica. (BENKÖ, 1981, p. 13).

Eis pois, os dois grandes paradigmas que representam as posturas acadêmicas que discorrem acerca da psicologia da religião: os que a enxergam 
como algo danoso e ruim e aqueles que a veem como algo importante e até necessário para a saúde pessoal e social. Segundo Croatto, a primeira dessas grandes vertentes é exemplificada pelo pensamento de Sigmund Freud (18561939) e seus seguidores:

que interpretavam a experiência religiosa como um produto (sobretudo negativo) de conflitos ancestrais (algo equivalente à infância da humanidade, em comparação à do indivíduo). Um desses conflitos - o complexo de Édipo - radicaria na sublimação do originário pai assassinado. Para apagar as marcas do crime e expiá-lo, o ser humano criou leis de incesto e exogamia, sublimou a imagem do pai na figura do totem e na festa totêmica (repetição ritual e libertadora do assassinato do pai). (CROATTO, 2001, p. 20).

Desta forma, para o autor da psicanálise, o surgimento da religião não passaria de uma mera ilusão, semelhante ao sono, ao delírio, ou à neurose obsessiva, que habitaria por excelência, o reino do imaginário. Desta forma, Deus representaria o imaginário de um pai onipotente.

É possível vislumbrar no discurso de Freud - encontrado em obras como Totem e tabu (1913) e Moisés e o monoteísmo (1939), uma forte influência do discurso de Ludwig Feuerbach (1804-1872), e sua obra A essência do cristianismo, onde acredita que Deus é a projeção de nosso pai terreno e o Céu a de nossa sociedade, como deveriam ser. Também vislumbra-se em Freud um pouco do discurso Iluminista de Kant que defendia que o homem teria chegado à idade adulta, e portanto à emancipação das ideias religiosas, por meio da razão.

Religião e razão, religião e ciência, ou ainda, espírito religioso e espírito científico sempre foram objeto de muita discussão (seja como diálogo ou como conflito). Nesse sentido:

O espírito religioso provoca uma atitude específica para com os assuntos do mundo; perante os assuntos religiosos, eles se detêm um instante, hesita, e, finalmente, cruza-lhes o limiar... Quanto maior o número de homens a quem os tesouros do conhecimento se tornam acessíveis, mais difundido é o afastamento da crença religiosa, a princípio somente de seus ornamentos obsoletos e objetáveis, mas depois também de seus postulados fundamentais. (FREUD, 1997, p. 61).

Noutra vertente, que pode ser observada entre os estudiosos da religião, encontra-se a figura de Carl Gustav Jung (1875-1961). Muito embora tenha iniciado seus estudos psicológicos sob a tutela de Freud, dele se afastou em 1913. O tema que os unia era a questão do inconsciente. No entanto, o que os diferenciava é que para Jung, a expressão do inconsciente assumia formas diferentes. Como afirma Benkö, "Na sua concepção é errado pretender 
reduzir tudo ao instinto sexual (BENKÖ, 1981, p. 51). Nele, verifica-se uma abordagem mais positiva acerca da religião:

Um de seus pressupostos é o do "inconsciente coletivo", mais arcaico do que o inconsciente individual; é uma espécie de memória ancestral, de sedimentação das vivências da primeira humanidade (a mesma preocupação pelo originário manifestada por Freud!) e que se formaliza em profundas marcas psíquicas: os arquétipos (animus/anima; o puer aeternuus ou jovem/donzela, com sua contraparte, o herói; o sábio; o Si Mesmo e seu correlato, o divino). Os arquétipos do inconsciente seriam a fonte, tanto dos sonhos como dos mitos da religião. (CROATTO, 2001, p. 20-21).

O que precisa ser destacado nas teses de Jung, é que ele sempre insistiu na existência de uma relação entre os mitos e a religião. E essa associação serviria para poder criar uma consequência altamente positiva na psique das pessoas. Ela produziria um papel estabilizador na constituição da personalidade $^{3}$, ou seja, no Selbst ou Si Mesmo, que é diferente do Eu. Sua exposição sobre esse tema pode ser encontrada em sua obra Psicologia e religião ocidental e oriental, lançada no Brasil em 1990, ou em Introdução à essência da mitologia, ainda não vertida para nossa língua.

Para encerrar essa questão, indica-se o significativo texto de David Atkinson, para quem, "For Christian pastors, the psychologies of religion can offer insights into aspects of religious atitudes and behaviour" (CAMPBELL, 1990, p. 225). Segundo postula Atkinson, uma significativa questão para ser examinada pelos pastores é a relação entre a teologia cristã e a psicologia, e a estrutura interpretativa pela qual as teorias psicológicas e os resultados experimentais são valorizados nas comunidades. Mas não se pode mais, nos dias de hoje, abrir mão dessa ferramenta fundamental para observar e compreender melhor os fenômenos religiosos nas comunidades e na sociedade em geral.

Nesse sentido, Rosileny Alves dos Santos, na obra citada, discorre sobre o método de correlação em Paul Tillich quando diz:

Os conceitos coincidentes da psicologia analítica de Carl Gustav Jung com conceitos da teologia sistemática de Paul Tillich possibilitam o surgimento de alguns outros conceitos para a análise da experiência religiosa de sentido... Esse método proporciona um caminho de livre trânsito entre a racionalidade e o estado extático. (SANTOS, 2004, p. 102). ${ }^{4}$

3 Deste entendimento é que nasceu o título do presente artigo, pois, cremos e a psicologia confirma, o ser humano é um todo complexo. Nesse sentido, quanto mais integrado ele for consigo mesmo e com o todo que o cerca, mais qualidade de vida ele terá.

4 Aqui entende-se o estado extático, ou ainda o êxtase religioso, como um momento bom sentido pela pessoa que está em oração. Pensemos nas sensações positivas provocadas por este momento, seja ele individual ou coletivo com vistas ao processo terapêutico / curativo da pessoa que ora. 
Estado extático esse provocado por um momento de profunda oração e contemplação do mistério, seja ele provocado por repetições de mantras, canções ou ainda pela egrégora religiosa coletiva. E aqui fala-se em mistica, uma característica comum e especial existente em todas as religiões que é justamente esse momento profundo de comunhão com Deus (do ponto de vista judaico-cristão), ou ainda de comunhão com o mistério, com a criação, com a dimensão do sagrado, com a natureza etc. Aqui temos uma enorme variação de expressões e definições de acordo com a religião a que se faça referência. Fato é, a dimensão mística é elemento comum em todas as religiões, basta a simples retomada do conceito religare para se chegar a essa afirmação.

Mas seria o êxtase religioso apenas um sentimento momentâneo?.

O "êxtase" ao qual Tillich se refere é um estado extraordinário da mente no sentido em que ela transcende sua situação ordinária. Êxtase não é negação ou anulação da razão, mas superação dos limites racionais. É compreender a possibilidade de a razão ir além de si mesma, além da estrutura sujeito-objeto, sem tornar-se irracional ou antirracional. O êxtase, então, difere do mero "entusiasmo" ou da autoexcitação religiosa produzida artificialmente e que frequentemente intentam anular a razão e confundir a presença do Espírito divino com superstições e desequilíbrios mentais. Tillich não nega que o êxtase inclui um forte aspecto emocional, mas considera um grave erro reduzir êxtase a emoção. (CALVANI, 1998, p. 85).

Contudo, tudo o que vimos até aqui só tem sentido quando se busca essa integração do humano, ou seja, consigo mesmo e com o meio que o cerca, com vistas a fazer deste mundo um lugar melhor para se viver, um lugar com mais amor. Não existe uma espiritualidade desencarnada, esta seria alienação, afinal, há duas hastes na cruz do calvário, uma fala do céu, outra fala da terra. Jesus nunca fez a separação entre céu e terra, sempre ensinou como melhor se deve viver cá na terra, sempre falou de integração:

Ora, não nos relacionamos com esses elementos como se fôssemos corpos desencarnados. Não há desencarnação no cristianismo. Há, isso sim, encarnação. E encarnação significa a compreensão de que só podemos ser cristãos enquanto corpos que vivem em relação primordial com os quatro elementos. A educação visível nos elementos é encarnada. E espírito é sempre corpóreo: não flutua por aí como um fantasma, nem anda ao redor dos vivos como sugere boa parte da imaginação popular. O Espírito é o corpo. Ou, em outras palavras, é o corpo que é espiritual. Não se pode dizer que o espiritual seja a ausência do corpo. (MARASCHIN, 1996, p. 124).

Nesse sentido, é preciso cultivar uma espiritualidade encarnada, o que passa pela valorização das coisas mais simples da vida, o ar que respiramos e que nos dá a vida, o fogo que nos aquece e prepara o alimento, a água que 
tudo purifica e onde somos gerados (em uma bolsa de água), por fim, a mãe terra. Valorizar tudo isso e contemplar tudo isso como presente do Criador é sem dúvida ter uma espiritualidade encarnada.

E não se pode deixar de falar de uma espiritualidade encarnada que nos fala de relacionamento conforme supracitado, sem falar da liturgia celebrada nas comunidades, momentos especiais para celebrar a vida em toda a sua plenitude. Nesse sentido, a liturgia é sempre relacional, seja na esfera individual ou coletiva, pois mexe com os sentidos daquele que ora e provoca a partilha da vida, ou seja o cuidado com o(a) outro(a). A liturgia fala, portanto, de solidariedade, de partilha, de mesa, de refeição, e onde há refeição não há fome e onde não há fome há cuidado mútuo e portanto, o exercício da partilha que cura e que promove vida. Na liturgia celebrada se olha para os outros, sente-se o gosto do pão e do vinho que provoca uma boa sensação em nosso corpo e alma, um momento especial e prazeroso, sendo este como uma pitada do que se acredita que será o banquete na eternidade. Sente-se também e ouve-se o som das canções e dos instrumentos musicais que levam a todas as pessoas ao momento extático de oração. O povo feliz também se abraça, se toca e deseja a paz. Também na liturgia se sente cheiros, seja do incenso, das velas utilizadas, do pão e do vinho. Todas essas sensações e gestos fazem parte então do que se pode entender como a "espiritualidade do corpo". (MARASCHIN, 1996, p. 125). O que demonstra mais uma vez o caráter da nossa espiritualidade que é encarnada, solidária, curativa e, portanto, carregada de momentos terapêuticos.

Nesse sentido, o hábito de participar das liturgias nas comunidades tem um aspecto educacional que ajuda o ser humano a ser mais humano, uma vez que se entende ser a Educação um ato de humanizar.

\section{Conclusão}

Conforme enunciado, e metodologicamente falando, procuramos no presente artigo a) definir a questão (definir o que é Psicologia da Religião) e, para isso perpassamos pela breve definição do que vem a ser a experiencia religiosa que ocorre em nossas comunidades, experiencia essa que é êxtase, porém não é transe, é pratica pastoral comunitária antiga e atual e faz parte da mística religiosa. Discorremos também sobre os mais variados aspectos e áreas do humano com vistas a sua integração, sua imanência e transcendência, uma vez que cremos ser este caminho da integração o qual possibilita um melhor entendimento de si mesmo e do meio onde vivemos e, portanto, tal integração promove uma melhor qualidade de vida. Desse modo, fomos 
caminhando para o ponto b) delineando o raio de ação, onde vimos qual é o papel da psicologia da religião, quais fenômenos que o psicólogo deve levar em consideração em sua análise dos casos e falamos também sobre a integração dos saberes, noutras palavras, que psicologia e religião andam de mãos dadas, de acordo com os referenciais teóricos utilizados em nossa pesquisa, com exceção de Freud. Em nosso último ponto c) os principais caminhos a tomar, reconhecemos que há posições antagônicas no que tange ao caminhar junto da psicologia e da religião, sobretudo, em Freud. Por outro lado, e muito mais presente em nossa pesquisa, vimos que há posicionamentos na direção de uma integração entre esses saberes conforme supracitado. Nesse sentido, o êxtase que tem total relação com a dimensão da espiritualidade, têm também profunda relação com a experiencia religiosa e tanto na esfera individual quanto coletiva e é isso o que o psicólogo irá estudar quando analisará os fenômenos religiosos, sejam eles individuais ou coletivos. E aqui quando falamos em coletivo falamos das celebrações litúrgicas vividas nas mais variadas comunidades, ou seja, uma prática pastoral comunitária antiga e atual que tem a força de ser terapêutica na vida daquele que professa a sua fé, além de ter sem dúvida alguma o aspecto educacional com vistas a ajudar e ensinar o ser humano a ser cada vez mais humanizado, logo, concluímos também que educação e espiritualidade caminham de mãos dadas. Por fim, esperamos que o presente artigo lhe tenha ajudado em seus estudos a cerca deste tema tão amplo e complexo: a psicologia da religião como instrumento da integração do humano.

\section{Referências bibliográficas}

BENKÖ, A. Psicologia da religião. São Paulo: Loyola, 1981.

CALVANI, Carlos Eduardo B. Teologia e MPB. São Paulo: Loyola; Editora da Umesp, 1998.

CAMPBELL, Alastair V. A dictionary of pastoral care. London: SPCK, 1990.

CROATTO, José Severino. As linguagens da experiência religiosa: uma introdução à fenomenologia da religião. São Paulo: Paulinas, 2001.

ELWELL, Walter (ed.). Enciclopédia histórico-teológica da igreja cristã. Vol III. São Paulo: Vida Nova, 1990.

FARRIS, James Reaves. Psicologia e religião: uma análise de práticas religiosas. Caminhando, São Bernardo do Campo, v. 7, n. 1, p. 23-37, 2002.

FORTE, Bruno. Um pelo outro: por uma ética da transcendência. São Paulo: Paulinas, 2006.

FREUD, Sigmund, O futuro de uma ilusão, Rio de Janeiro: Imago, 1997.

GOTO, Tommy Akira. O fenômeno religioso: a fenomenologia em Paul Tilich. São Paulo:

Paulus, 2004. 
HOUTART, François. Mercado e religião. São Paulo: Cortez, 3003.

MARINO JUNIOR, Raul. A Religião do cérebro: as novas descobertas da neurociência a respeito da fé humana. São Paulo: Gente, 2005.

JUNG, Carl G. Psicologia e religião. 6. ed. Petrópolis: Vozes, 1999.

MARASCHIN, Jaci. A beleza da santidade: ensaios de liturgia. São Paulo: Aste, 1996.

ROSA, Merval. Psicologia da religião. Rio de Janeiro: Casa Publicadora Batista, 1979.

SANTOS, Rosileny Alves dos. Entre a razão e o êxtase: experiência religiosa e estados alterados de consciência. São Paulo: Loyola, 2004.

Submetido em:5-8-2020

Aceito em:16-10-2020 